\title{
French Silk Varieties in Eighteenth Century
}

\author{
Jialiang Lu ${ }^{1} \&$ Feng Zhao ${ }^{1,2}$ \\ ${ }^{1}$ School of Fashion and Art Design, Donghua University, Shanghai, China \\ ${ }^{2}$ China National Silk Museum, Hangzhou, China \\ Correspondence: Feng Zhao, China National Silk Museum, Hangzhou, China. Tel: 86-139-5806-6182. E-mail: \\ $1007043621 @$ qq.com
}

Received: December 6, 2020

Accepted: December 19, 2020

Online Published: December 30, 2020

doi:10.5539/ass.v17n1p53

URL: https://doi.org/10.5539/ass.v17n1p53

\begin{abstract}
The design of French silk was very exquisite. Which has formed a clear specification and strict classification system even teaching materials in Eighteenth Century. Based on the existing material objects and teaching materials, this paper systematically sorts out the variety system of French silk fabrics, makes a detailed classification of varieties, and analyzes the political factors of the prosperity and development of French silk industry in the 18th century.
\end{abstract}

\section{Preface}

The history of silk in France was not very long, but it indeed reached the peak of the world and was extremely glorious.

Especially around the 18th century, which can be divided into four periods. For starters, the country supported silk industry by making policies under king Louis XIV's reign, and then, lots of technique innovations appeared during the reign of king Louis XV. What's more, flourishing period of silk in France started when Louis XVI succeeded. However, it was the French Revolution that made a huge decline of silk industry. Finally, Napoleon I decided to bring it back to glorious again.

Looking back to the process of how silk industry in 18th century France reach the peak of world silk industry. Firstly, we should be attributed to the industrial policy of France to Lyon silk made by French king and the royal family, it was them who set up protection system and quality standards, at the same time, they made a large number of orders, without them, Lyon and French silk may not have such glory. In addition, Lyon's technological innovations, variety perfections and design renovations also play a significant role in developing French silk.

By the 18th century, French silk, especially in Lyon, developed a lot and had the most complete industry chain and variety category.

\section{Fabric Classification}

The classification of French silk was very exquisite, which has a clear specification and strict classification system, and they were written into textbooks at that time.

The production of a silk fabric needs to go through many complicated process. The production is complicated before and after the process, which is divided into the preparation process and the weaving process of the yarn. As shown in the Figure1, from the beginning of mulberry sericulture, silk has been extracted from silkworm cocoon through silk reeling process, and after a series of yarn processing, silk has become a silk thread for weaving, arranged into warp shafts and into the weaving process.

The weaving process of silk products is divided into two large systems, plain fabrics and jacquard fabrics. The two types of products are woven with different looms, and different from the way of the yarns movement. The heddle control the yarns paths to weave a plain fabric, generally the fabric weave is sample, first of all, according to the product application design products, including raw materials, color density, then design organization, computer charting, production lines, and weaving. The yarns of jacquard fabric is controlled by card source, and the weave is complex, the pattern is colorful, similarly the first step is design the products, and according to the request to design pattern, then get the pattern grid, design process, the process including organization, weft pick information and weaving on the base of card source. 
There are many kinds of French silk fabrics, mainly including the following categories: Plain fabric、 jacquard fabric, velvet, lace, chine, moire, ribbon, Woven photograph etc.

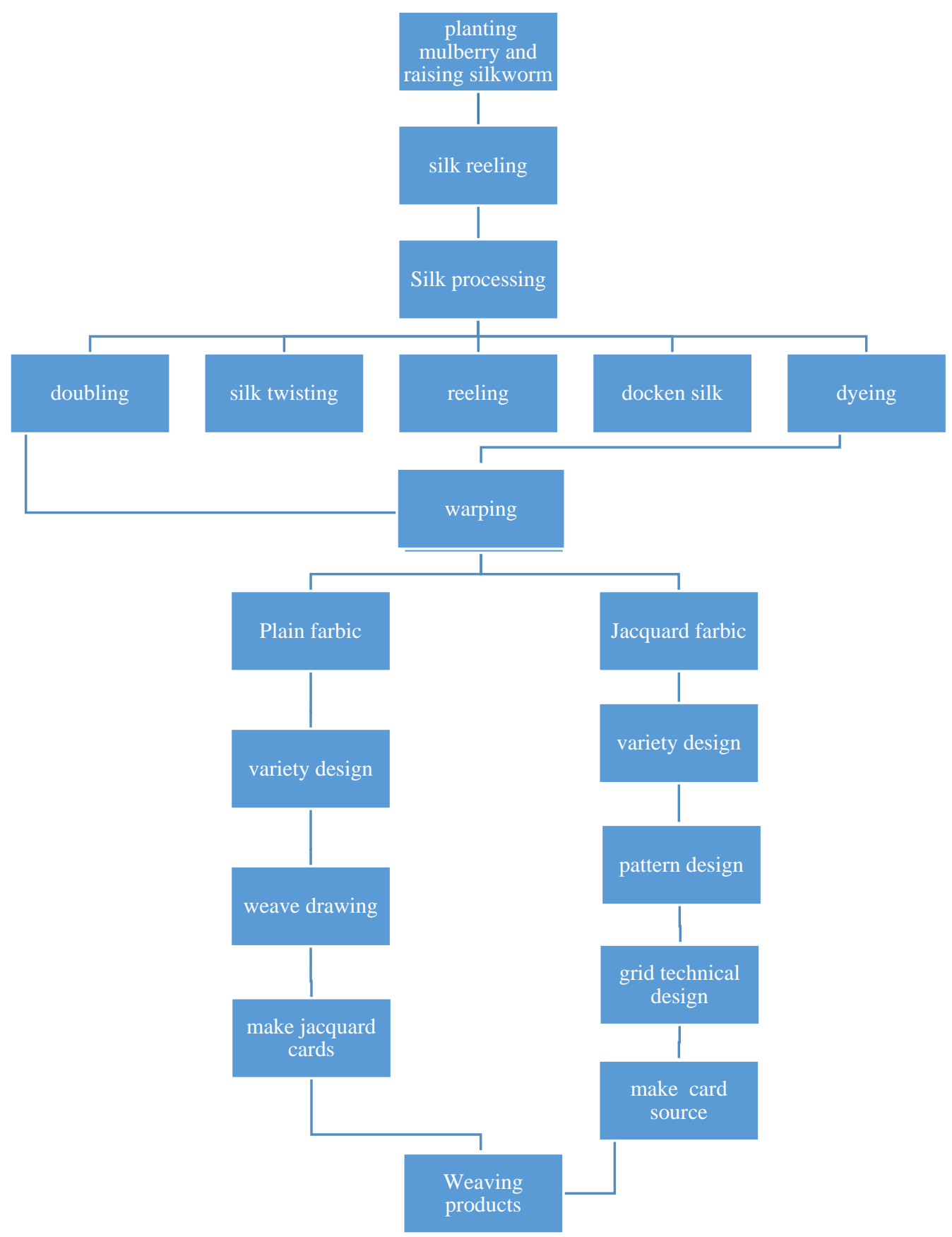

Figure 1. Weaving process

\subsection{Plain Fabric}

Plain fabric is a major category in the woven fabric, the rise of the warp through the heald frame to achieve and form the Cloth-fell, Interweave with weft to form fabric.

The plain fabric is limited by the number of heddles in the heald frame, so the organization is relatively simple. The common weave has plain, twill, satin, dobby fabric and so on (Figure 2). 

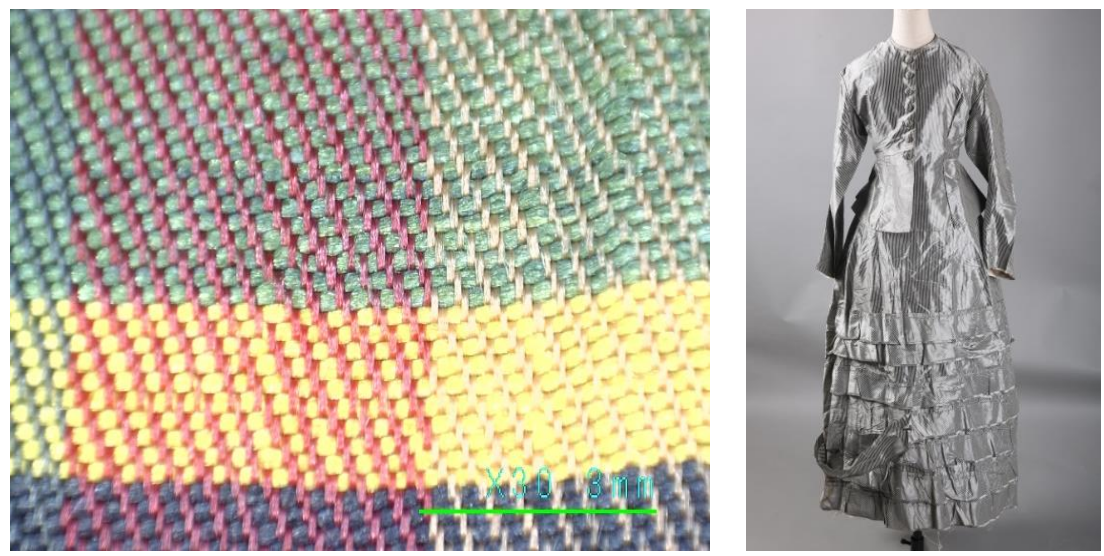

Figure 2. Plain Fabric and Clothing

\subsection{Jacquard Fabric}

\subsubsection{Damask}

Damask is a reversible figured fabric of silk (Figure 3). Longitudinal (warp) and transverse (weft) yarns usually in monochrome and mostly are stain weave, the fabric varies in luster according to the position of the observer. There are also two-color damasks had contrasting color warps and wefts, and polychrome damasks added gold and other metallic threads or additional colors as wefts.

The word "damask" first appeared in records in a Western European language in the mid-14th century in French. It from the heart of Damascus. Damascus is one of the five basic weaving techniques of Byzantine and Islamic weaving centers in the early Middle Ages. From the 14th to 16th century, most damasks were woven in monochrome. The invention of the Jacquard Loom at the beginning of the ninetieth century meant that Damask could be mass produced. The most common in table linens and furnishing fabrics, but they are also used for clothing.
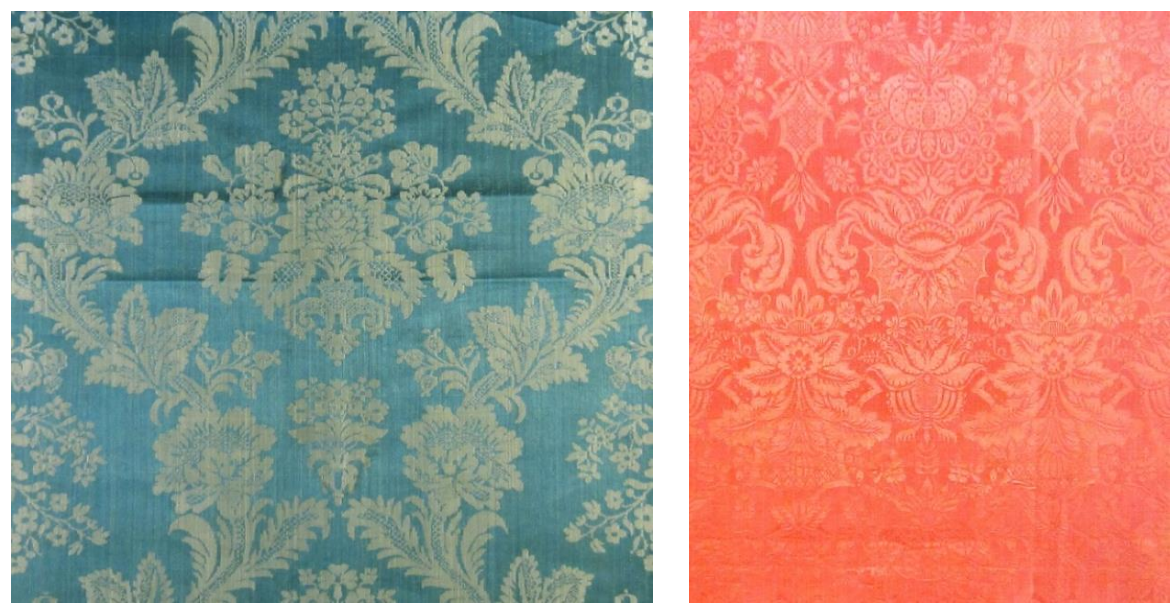

Figure 3. Damask

\subsubsection{Brocade}

Brocade is a kind of richly decorative shuttle-woven jacquard fabric, usually forming by interweaving a group of warp and multi-group weft yarns. At least one set of weft and warp threads are woven into the ground of the fabric, the other groups of colored or metallic weft threads are woven into the flowers of the fabric through the brocading techniques, which is a purely manual technology. A discontinuous brocade is where the weft yarns weaving round and back in the patterned areas, and producing the effect of low relief or the style of embroidery on its face.

Brocade is also an important fabric during the Renaissance. In the 18th century, Jakarta from Lyon made a pedal jacquard loom, which became an important innovation in French history. The complexity and high quality of luxurious silk fabrics caused Italy and France to become the most important and superior manufacturer of the finest silk fabrics for all of Europe. During 19th century Brocade fabrics are available to the rich and nobility. Brocade fabrics are mostly for upholstery and draperies, also used for evening and formal clothing. 


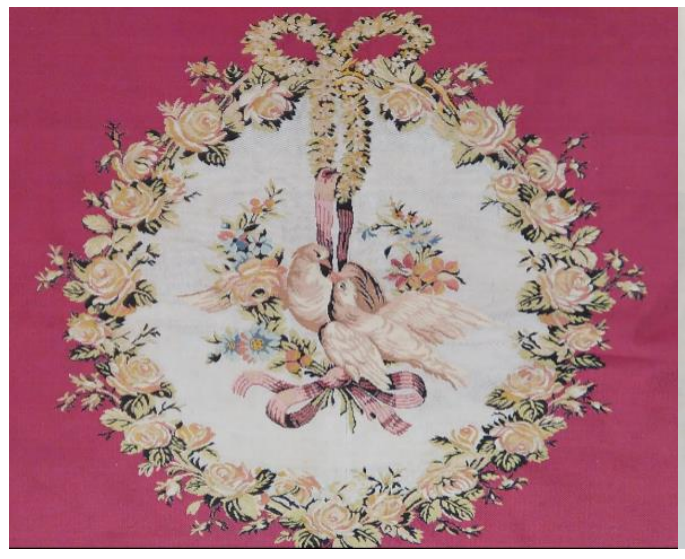

The face of brocade

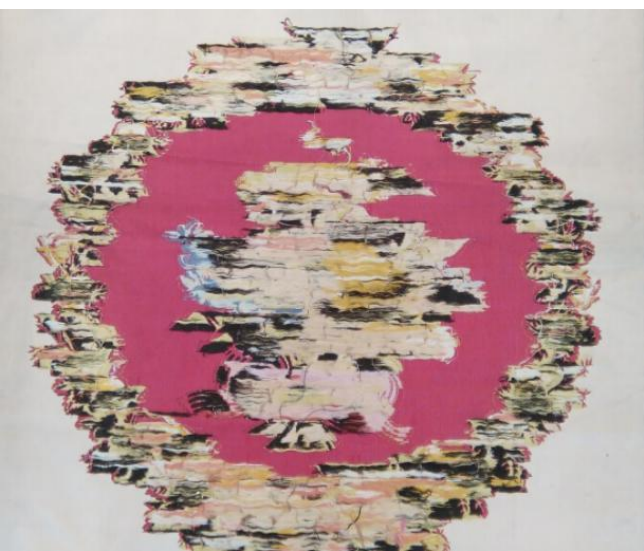

The back of brocade

Figure 4. The front and back of brocade

\subsection{Velvet}

Velvet is a type of woven fabric with a short dense pile. It is short, in clusters and very dense. Velvet can be made from several different kinds of fibers, traditionally, it was mainly made of silk in the 17th-19th century. Velvet originated from the Far East. It was thought as a fit material for ecclesiastical vestments, royal and state robes, and so on. Velvet was a luxury in 18th-century France and synonymous with aristocracy.

The fluff comes from Loop pile, and it's formed by the "Rod weave". That is, weaving the weaving rods into fabrics while weaving the weft, so that the warp on the pole can float on the pile. Draw the pole out and form a coil. According to the pattern, you can choose to cut the coil or not, the coil forms a villi when cutting. Figure 5 is a schematic diagram of "Rod weave" in the textile textbook published in France in 1862.

Because of its unusual softness and appearance as well as its high cost of production, velvet has often been associated with nobility. It exhibited the splendid softened and depth of dye-color. It was been thought as a fit material for ecclesiastical vestments, royal and state robes, and sumptuous hangings at that time. The earliest sources of European artistic velvet were Lucca, Genoa, Florence and Venice, which continued to send out rich velvet textures. Somewhat later the art was taken up by Flemish weavers.
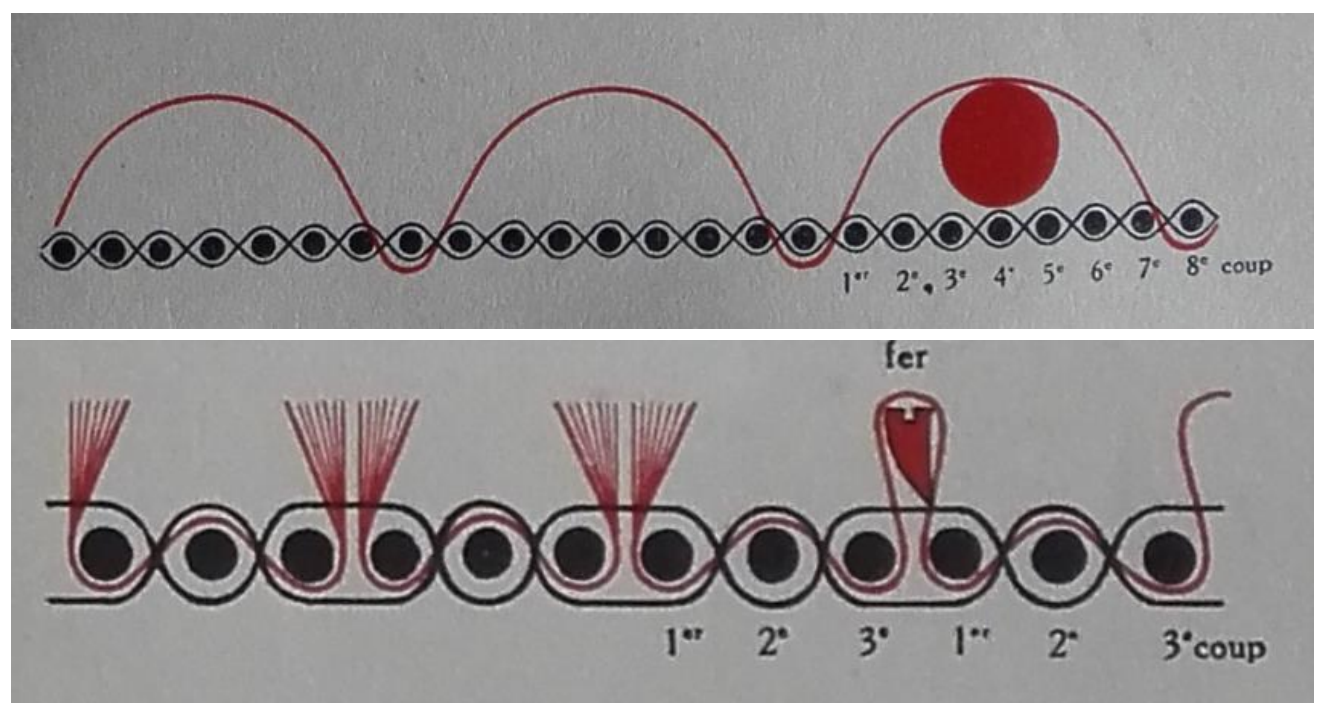

Figure 5. Schematic diagram of "Rod weave"

\subsection{Ribbon}

Ribbon is a kind of narrow fabric or tubular fabric made of a variety of yarn as raw materials, and the general width is less than $40 \mathrm{~cm}$, you can weave a lot of ribbons at the same time on the weaving machine. Ribbon is widely used in apparel and accessories, shoe materials, bags and so on.

At the end of the 16th century, there was a machine that could weave several ribbons at the same time. These 
machines caused discontent and riots among weavers, so the state had to ban the use of these machines. At the same time, in Europe's major industrial centers, ribbon looms were banned. In 1676, the loom was brought to London. Although its introduction caused some disturbance, no one objected. In 1745, Joseph Kay, the inventor of the flying shuttle, and Joseph Stell jointly obtained a patent for improving the ribbon loom. Since then, it has been greatly developed.
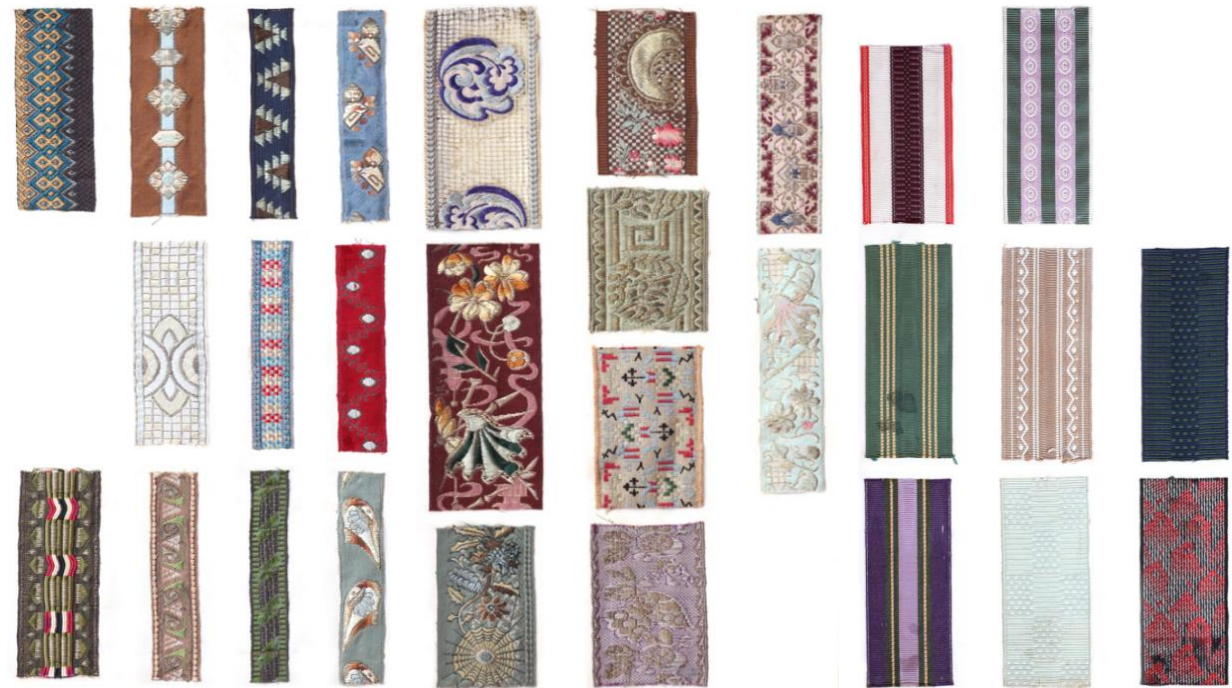

Figure 6. Ribbon in fabric book

\subsection{Woven Photograph}

Woven photograph such as portraits and landscapes which are made by silk, including silk flowers, animals, text and so on. Woven photograph originated in Europe in modern times, producing on jacquard machines, it can be divided into two types, black-and-white as well as polychrome, using black-and-white or colored warp/weft threads, obtaining distinct effect by changing the texture of fabrics, that's how it shows vivid character or scenery on the surface of the fabric, just like photos, they can be used for interior decoration and ornamental.

Modern image fabric originated in Europe. The emergence and development of jacquard loom "Coordinate paper design method" as the main content of Modern Italian craftsman technology, through the dot lattice on the paper, can make two or more color lines through the density of weaving points to show the gradual transition of black and white, light and shade and color. The completion of the jacquard pattern plate and continuous jacquard technology provides technical conditions for weaving photographic images of silk paintings, making European image fabric unprecedented prosperity and weaving A large number of exquisite image fabrics including trademarks, bookmarks, portraits, landscapes and words, flowers and so on have been produced.
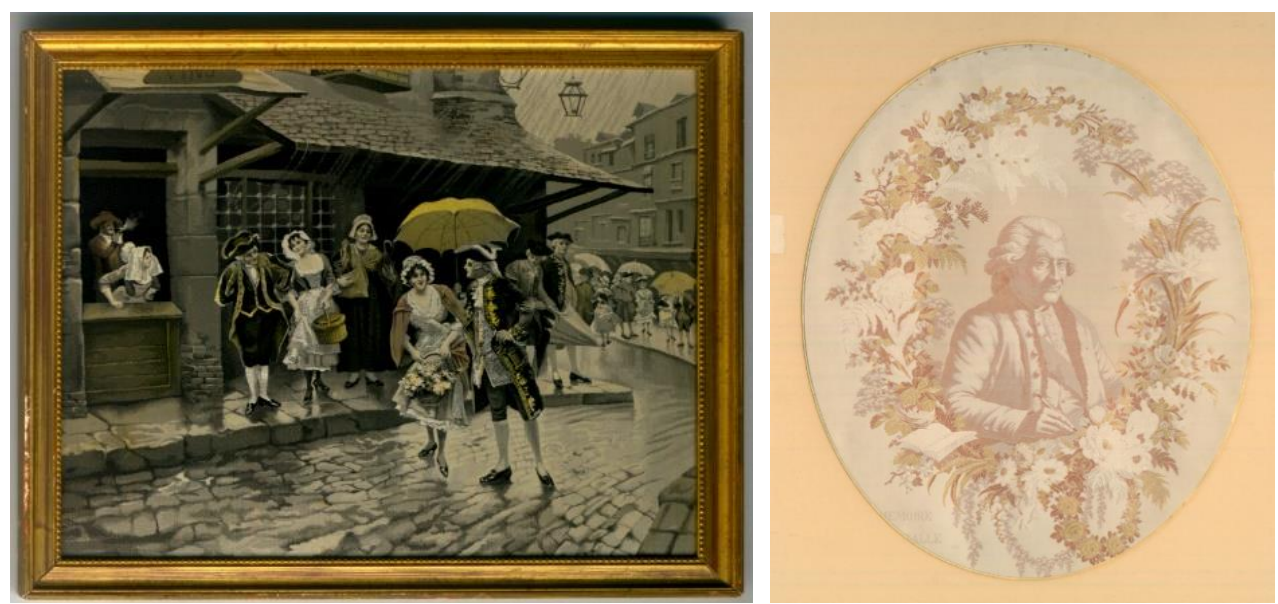

Figure 7. Woven photograph

Among them, Thomas Steven, an Englishman, founded a silk weaving factory, which not only produced a large number of photographic images, landscape oil paintings and other colorful images, but also developed silk postcards, greeting cards, ribbons and silk cultural souvenirs, which had a great influence in Europe. Therefore, 
in English, it is also called "Stevens painting". The European landscape fabrics were once flourishing until the middle of twentieth Century, and the products were reduced to a low level. But the advanced technology of weaving technology remained.

\subsection{Special Varieties}

In addition to the above conventional fabrics, there are many special varieties of French silk fabrics, such as chiné、 moire etc.

\subsubsection{Chiné}

As a relatively small variety of silk, the characteristics feature of chiné silk consists in the vague prints, just like IKAT fabrics in southeast Asia, on the one hand, it's because the silk warp is printed with harmonic colors previously to warping and weaving, on the other hand, the tention of warp yarns while weaving cause the distortion of the pattern.

In the weaving of warp printing fabric, the warp beam is first placed on the loom, and then it is woven with plain weave. Then, it is spread on the printing table, and the pattern is printed by common printing method. Then the warp yarn is removed and put on the shaft again for weaving.

Chiné silk warp can be woven either with white or colored filling, and the different combinations in color can be readily understood, the use of different weaves will also result in novelties. These all explains why chiné silk is meeting with such universal favor with the public. Figure 8 shows the chiné silk products of plain fabrics on the left and jacquard fabrics on the right.

Chiné fabric is mainly used for women's dress, decoration and men's tie in fashion design.

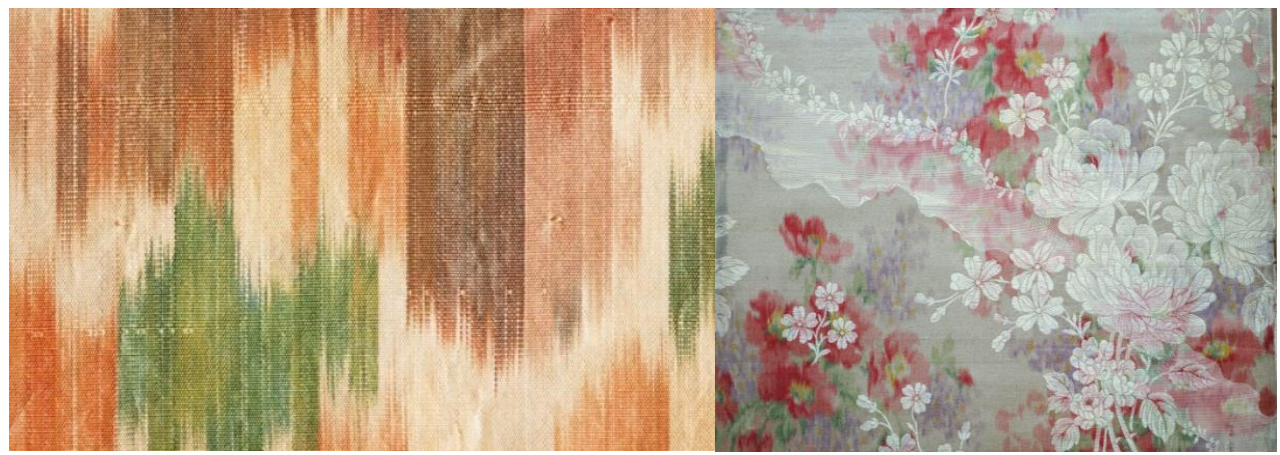

Figure 6. The chiné silk products of plain fabrics and jacquard fabrics

\subsubsection{Moire}

Gauffre silk also known as moire, is a fabric with a wavy appearance, which is smooth and glossy, and produced mainly from silk, but also wool, cotton and rayon.

Forming the appearance of water ripple effect usually have two ways. One method is to make the fabric through the finishing technology of calendering. After the fabric is folded into half from the outside to the inside, the rib roller is used for calendering on the special calendering machine to produce the effect of water wave, and then the surface of the fabric is polished by the roller to make the fabric more smooth and glossy. Another way is applying high temperature and high pressure condition to the fabric, after that, warp and weft reflects the light in different directions, forming a similar pattern of water waves.
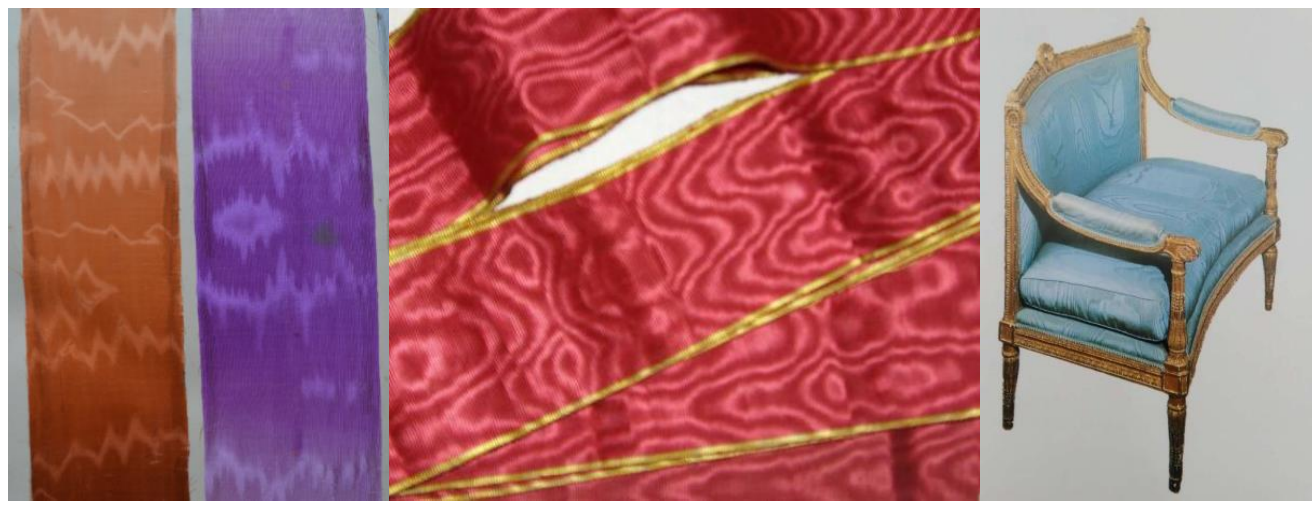

Figure 9. Moire and its application 
Moire fabric is more delicate than fabric of the same type that has not gone through the calendering process. Also, contact with water removes the watermark and causes staining. Moire feels thin, glossy and papery due to the calendering process.Generally moire is made out of fabrics with a good body and defined ribs, such as grosgrain. Fabrics with defined ribs show the watered effect better than smooth fabrics like satin. Taffeta also works well.The moire effect may be obtained on silk, worsted, or cotton fabrics, though it is impossible to develop it on anything other than a grained or fine corded weave. Compared with untreated fabrics, moire fabric is more delicate, lustrous and widely used in decorative fabrics and clothing (Figure 9).

\subsection{Other Fabrics}

\subsubsection{Lace}

Lace is a delicate fabric made of yarn or thread in an open weblike pattern, some similar to knitted fabric, but the lace is made of a knitting needle or a group of bobbin threading, knitting or twisting, made by machine or by hand. Lace is widely used in a variety of textile and apparel decoration, up to the expensive accessories, down to cheap decorations, and it's also varied in the production process and style design.

It can be divided into three types: Shuttle lace, needlework lace and woven lace, the former two appeared in the late 15 th or early 16 th century. At that time, the best and most fashionable lace was made in Italy, France and Belgium.
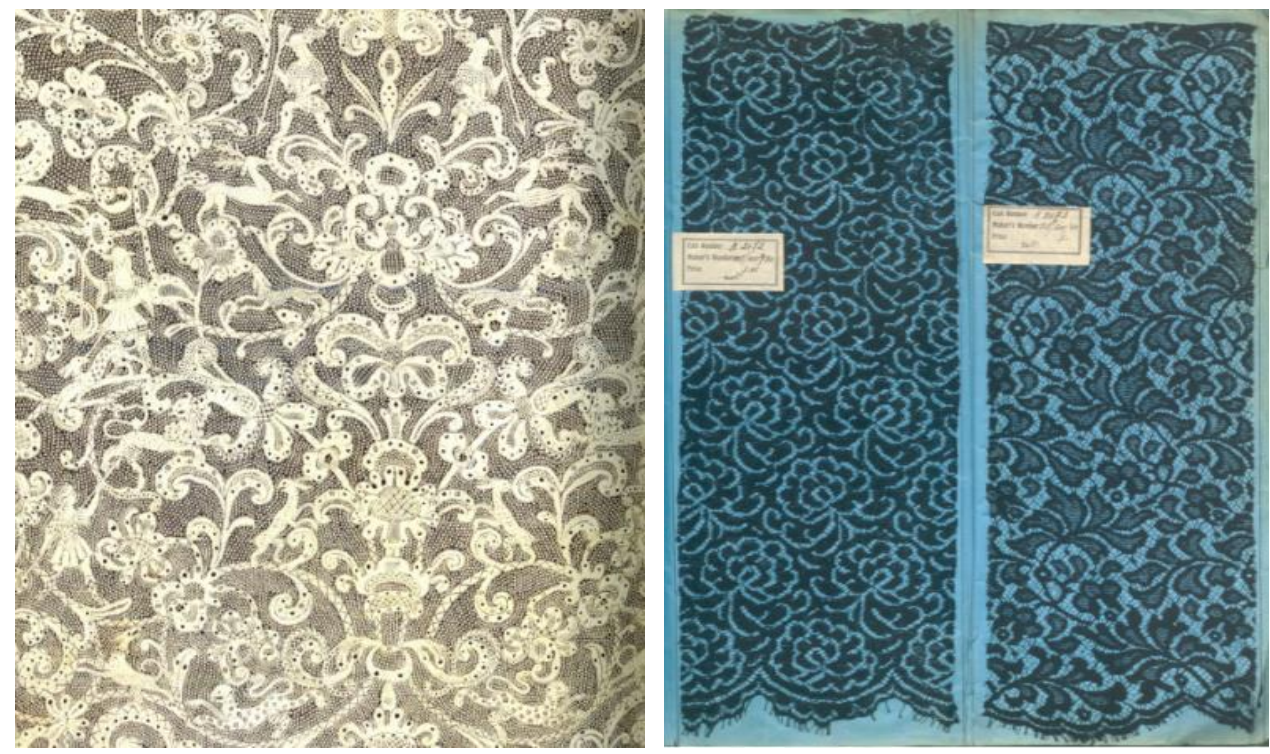

Figure 10. Lace

\subsubsection{Hand-drawing and Textile Printing}

Hand-drawing is the process of using certain tools, corresponding dyes, coatings and other auxiliary tools to create patterns in the embryo silk or garments by hand-painted way. It can be applied on the light ground with bright and soft colors, when drawing realistic and clear patterns. According to the process, there are hand-drawing and the silk painting of the powder production method.
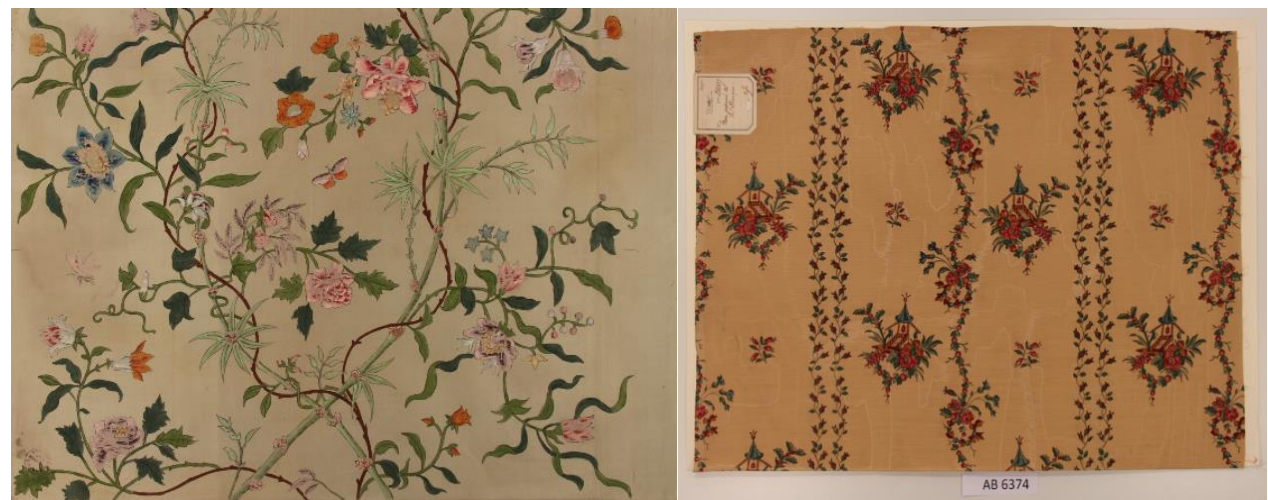

Figure 11. Hand-drawing and Textile printing fabric 
Textile printing is the process of applying color to fabric in definite patterns or designs. Traditional printing techniques come from hand-drawing. In printing, wooden blocks, stencils, engraved plates, rollers, or silkscreens can be used to place colors on the fabric. Colorants used in printing contain dyes thickener to prevent the color from spreading by capillary attraction beyond the limits of the pattern or design.

\subsubsection{Embroidery}

Embroidery is the handicraft of decorating fabric or other materials using a needle to apply thread or yarn. The main embroidery stitches can be classified in three types: flat stitches, loop stitches and knotted stitches. Some of the basic techniques or stitches of the earliest embroidery are chain stitch, buttonhole or blanket stitch, running stitch, satin stitch, cross stitch. Those stitches remain the fundamental techniques of hand embroidery nowadays. Machine embroidery appeared during the industrial revolution. By the mid-19th century, France accomplished the earliest machine embroidery, that is to apply a combination of machine looms and women hand-embroidering.

For thousands of years, wool, flax and silk have been used in traditional embroidery. Elaborate embroidered clothing, religious items and household goods are often regarded as symbols of wealth and status.

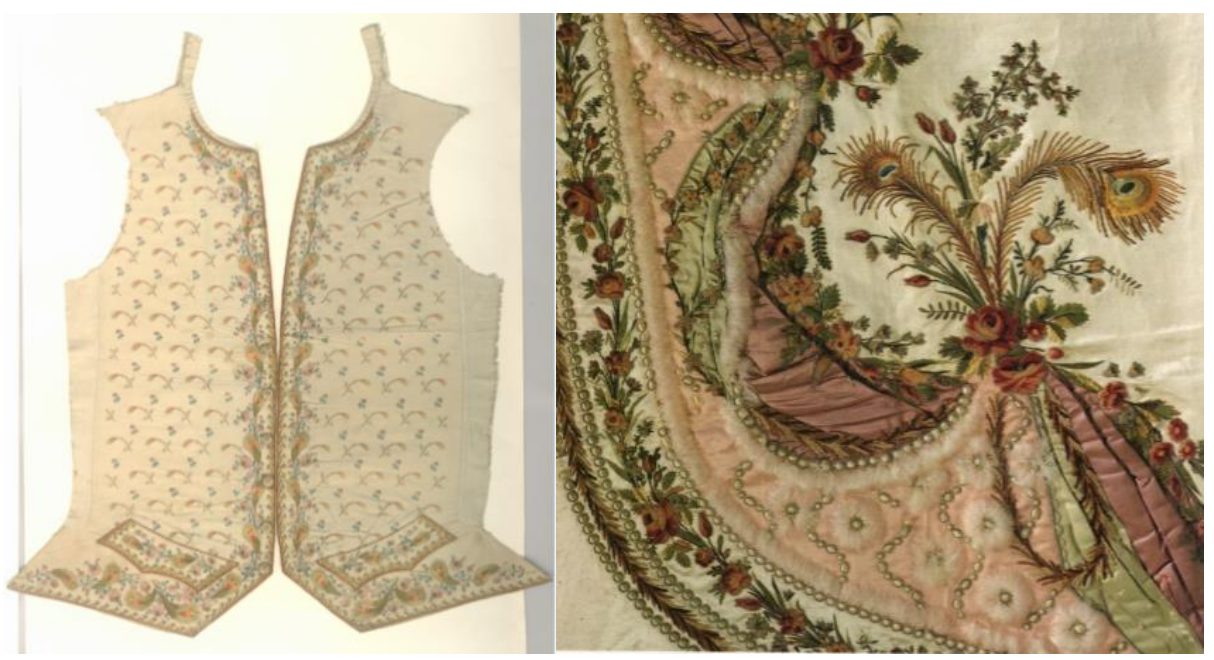

Figure 12. Embroidered vest and details

\section{Historical Reasons for the Development of French Silk}

The rapid development of French silk weaving industry in a short period of time has had a profound impact on the western textile history and economic history, and has also brought huge economic effects to enterprises and individuals. From the innovation points of the rapid development of French silk weaving industry, we can learn from it.

\subsection{Advanced Technology}

Relying on advanced technology. French silk weaving industry has a high content of science and technology, and its creative ideas rely on advanced technology and equipment to transform into novel and competitive silk products. We attach great importance to and introduce technology, promote development according to the national conditions, and cooperate with advanced science and technology to promote and promote the rapid development of silk weaving industry.

\subsection{Pay Attention to Personnel Training}

The most essential thing of a product is creativity and creativity, and the key to creativity is innovative talents. Creativity focuses on people's intelligence and ideas, and is the key and soul of the industrial development process. Pay attention to the cultivation of talents. In terms of concept, we should pay attention to the cultivation of innovative consciousness and ability, discover talents with unique creativity, encourage and support young creative behaviors, and provide them with multi-channel learning and exhibition. Through the exploration of talents and culture, the generation of creativity, and the final output of industrial development is huge efficiency.

\subsection{Cultural Innovation}

Rich cultural resources and profound cultural heritage are the basic conditions for industrial development. The competitiveness of national products of French silk weaving industry comes from the content of culture. Inherit the traditional culture, absorb foreign technology, and learn from foreign advanced ideas and projects. Take the 
patterns of silk fabrics as an example. The patterns themselves have the characteristics of story and art. The patterns of French silk products are not only based on the traditional elements of the country, but also add foreign elements. At the same time, when exploring the traditional culture, they should actively learn and introduce the advantages of foreign countries, and choose novel and unique topics, so that the traditional culture can continue to develop.

\section{Conclusion}

In today's France, silk is no longer the center of textile and clothing production, but silk still has a very high status in the hearts of the French people, especially Lyon people, or in the fashion industry. The production and design of a small amount of silk are mainly carried out around some famous French fashion and luxury brands. Traditional enterprises continue to copy and renovate the traditional style for French classic luxury decoration. New enterprises increase the combination of design and culture to produce clothing accessories for high-end people. French silk design is moving towards the future along with culture and history.

\section{References}

Ball, J. L. (1860). Cours de theorie de fabrique par. Paris: Lyon.

Étévenaux, J. (2016, July). Soierie en Auvergne-Rhône-Alpes Canuts, mouliniers et soyeux. Réalisation IDC.

Geijer, A. (1979). A history of textile art. Great Britain: W. S. Maney \& Son Ltd. https://doi.org/10.2307/1505876

Harris, J. (1993). 5000 years of textiles. London: British Museum Press.

Leavitt, T. W. (1969). The Hollingworth letters: technical change in the textile industry, 1826-1837. Cambridge: The Society for the History of Technology and the M.I.T Press. https://doi.org/10.2307/3102709

LOIR, J. (1923). Théorie du tissage étoffes de soie, Joannès. Lyon: DESVIGNE \&C1e Successeurs, Paris, Librairie Scientifique Desforges.

Maria-Anne Privat-Savigny. (2010). Musee des tissus de lyon. France: EMCC.

Poirieux, C. (2012). Lieux de la soie à Lyon. France: Lyonnaises d'Art et d'Histoire.

Poli, D. D. (2007). Twentieth-century fabrics-European and American designers and manufactures. Italy: Skira Editore S.P.A.

Tassinari, B. (2012). La soie à Lyon. France: Lyonnaises d'Art et d'Histoire.

\section{Copyrights}

Copyright for this article is retained by the author(s), with first publication rights granted to the journal.

This is an open-access article distributed under the terms and conditions of the Creative Commons Attribution license (http://creativecommons.org/licenses/by/4.0/). 